\title{
Segunda Linha: comunicação e sociabilidade na Linha 2 do metrô carioca ${ }^{1}$ Second Line: communication and sociability in line 2 of Rio de Janeiro's subway
}

Janice Caiafa I scintilla1@terra.com.br Doutora em Antropologia pela Universidade de Cornell, E.U.A, com Pós-Doutorado pela City University of New York. É pesquisadora do CNPq, coordenadora adjunta da CIEC (Coordenação Interdisciplinar de Estudos Culturais), poetisa e tradutora. Professora do Programa de Pós-graduação em Comunicação Social da Universidade Federal do Rio de Janeiro.

\section{Resumo}

Neste trabalho exploramos algumas especificidades da Linha 2 do metrô do Rio de Janeiro. Analisamos o contexto mais amplo do processo de urbanização na cidade, assim como características do projeto construtivo da linha e aspectos operacionais que a individualizam no sistema metropolitano. Indicamos em seguida que esse conjunto complexo de fatores que a constitui em alguma medida como a segunda linha do metrô carioca contribui para construir formas características de comunicação e de sociabilidade no contexto das viagens.

Palavras-chave: Processos Comunicativos; Sociabilidade; Metrô (Rio de Janeiro).

\begin{abstract}
In this text we explore a few specific aspects of Linha 2 (Line 2) of the Rio de Janeiro subway. We consider the larger context of the urbanization process of Rio de Janeiro as well as the characteristics of the construcion project of Linha 2 and its operation. We argue that all those aspects that to a certain extent make Linha 2 the second line of the system participate in shaping characteristic modalities of communication and sociability in the context of the subway rides.
\end{abstract}

Keywords: Communication Processes; Sociability; Subway (Rio de Janeiro). 


\section{Viajar na Linha 2}

No pequeno sistema de duas linhas do metropolitano do Rio de Janeiro, desenvolveu-se um contraste entre a Linha 1 e a Linha 2 que é sem cessar mencionado de diversas maneiras pelos usuários e que não se furta à observação direta. Ao mesmo tempo em que se apoia na experiência das pessoas - e por isso se apresenta em facetas variáveis e diferentes ênfases —, esse contraste se deve também em parte a características técnico-operacionais que separam as duas linhas.

Não é uma oposição simples que vamos traçar aqui — a variabilidade das falas dos usuários e as nuances que vão emergindo da observação-participação não permitiriam. Inclusive, como costuma ser com as linhas de um metrô, a Linha 1 e a Linha 2 se correspondem, se encontram a certa altura. Os passageiros das composiçóes se transferem de uma a outra linha e, de certo modo, se misturam, embora ingressem a partir de pontos do sistema que guardam diferenças entre si.

A estação de transferência tem sido, desde a ativação da Linha 2 (de construção posterior), a Estação Estácio. Hoje existe uma transição para uma outra forma de encontro entre as duas linhas que está sendo implementada pela concessionária que opera o metrô carioca. ${ }^{2}$ Esta passagem, junto a outros fatores que vêm agravando problemas antigos do metrô (sobretudo a superlotação), está se dando num cenário de tumulto operacional nunca antes experimentado nas viagens de metrô na cidade. Não é meu objetivo, contudo, tratar aqui da questão da transferência, mas sim explorar aspectos da sociabilidade e da comunicação que se geram no contexto da segunda linha do metrô.

A mudança na transferência entre as linhas envolveu também uma reconfiguração física e operacional no sistema. Foi construída uma ligação externa entre a Estação São Cristóvão, da Linha 2, e e a Estação Central, da Linha 1. Os trens que vêm da Linha 2 tomam esse "by pass" e entram na Linha 1 pela Central até a Estação Botafogo. Esse novo arranjo foi implementado em dezembro de 2009. Criou-se igualmente uma nova nomenclatura em que 10 estaçôes originalmente da Linha 1 (de Central a Botafogo) foram incluídas também numa nova Linha 2, como foi denominada. Apenas as estaçôes dos dois extremos da Linha 1 não são consideradas estaçóes comuns. Quem vem dessas estaçóes extremas tem que fazer transbordo. O que se verifica, contudo, é que na experiência dos usuários a Linha 2 continua sendo aquela que vai de Pavuna a São Cristóvão. As estações atualmente consideradas comuns são concebidas como pontos de chegada na Linha 1. Do ponto de vista sociocultural, portanto, a Linha 2 continua sendo aquela original, construída num setor da Zona Norte. É assim que é concebida pelos usuários, ao menos por enquanto, e é desta Linha 2 que tratamos aqui.

A Linha 2 serve regióes da Zona Norte da cidade, enquanto a Linha 1 vai da Zona Norte à Zona Sul, passando pelo Centro — regiôes mais privilegiadas em termos de urbanização e onde em geral estão os empregos das pessoas que embarcam na Linha 2. A Zona Sul é a área mais urbanizada da cidade e em que se concentra uma população de maior renda. Basta dizer que é a região que 
ladeia a praia. A Zona Norte, ao largo da brisa marinha, pode ter, por exemplo, um calor mais pesado durante o verão carioca — como de resto a Zona Oeste também. Esta é uma questão que se levanta no contexto das viagens de metrô, pois um fator definidor da experiência dos metrôs do mundo é a climatização. No Rio de Janeiro temos o calor da Zona Norte que entra em conflito com o vagão climatizado das estaçóes elevadas ou superficiais. Por outro lado, o calor durante as viagens pode ser ao mesmo tempo um problema operacional — já que por vezes o ar condicionado náo funciona - e que inclusive encontramos hoje cada vez mais também na Linha 1 .

A Linha 2 tem 15 estaçóes, todas elevadas ou superficiais, nenhuma subterrânea - de Pavuna até São Cristóvão, primeira parada depois da estação de transferência. ${ }^{3}$ Caracteriza-as a estrutura de concreto armado abrindo para o exterior, sendo que muitas tem também pastilhas, azulejos ou tijolos nas paredes das plataformas e nos mezaninos (parte intermediária entre a plataforma e o acesso às estaçóes), às vezes compondo desenhos. Engenheiro Rubens Paiva e Acari levaram apenas tinta colorida sobre parte do cimento, mas Maria da Graça, por exemplo, tem pastilhas translúcidas em vários tons de verde. É o que primeiro se apresenta para quem chega de trem na estação, as cores chamam e as pastilhas brilham. Tem também parede pintada com uma listra verde escura e retângulos cinza, como Inhaúma. Percebe-se todo um jogo com as pastilhas na sucessão das estaçôes - embora interrompido por algumas soluçôes mais precárias, onde o que realça é o bege sujo do concreto. Engenho da Rainha, por exemplo, é muito simples.

- E das estaçóes que você conhece? O que você acha do espaço? - perguntei a uma usuária com quem conversava na Linha 2.

- Eu acho, assim, que tem uma discriminação com as estaçôes da Linha 2. Eu acho que as da Linha 1 estão sempre sendo reformadas, têm mais opçôes de comércio, de estande. Sempre tem algum evento, alguma coisa. Da Linha 2 quase não tem nada. São mais esquecidas. Não são definitivamente esquecidas, mas são mais esquecidas do que da Linha 1. Acho que eles dão mais atenção à Linha 1. Porque vai pra Zona Sul, turista frequenta mais, então eu acho isso.

Diana, em entrevista na linha 1, comentou:

- A linha 2 é muito pior, né, assim, pior de estrutura, o vagão é muito pior, é uma falta, não sei, é impressáo, mas tem uma falta de cuidado com a Linha 2.

- A linha 1 é muito diferente — afirmou Laura, que frequenta mais a Linha 1 mas conhece as duas linhas.

- Diferente como?

- Tudo diferente. Tem mais conforto. O ar é melhor, mesmo o formato das estaçóes. Não sei, muito mais confortável. É pavorosamente diferente.

$\mathrm{Na}$ Linha 2, com o entorno entrando pelas estaçôes, são paisagens que vão se compondo a cada parada nas plataformas e nos mezaninos. São regióes mais remotas da cidade que se apresentam e se expóem com o traçado do metropolitano. A observaçáo desses tableaux aparece em muitas de minhas notas 
de campo e acredito que eles façam parte da ambiência que se gera na Linha 2, com seus processos sociais e materiais.

Entra o exterior e entram também as pessoas, que trazem por sua vez atitudes e desejos, se imbricando com o ambiente da linha e, em alguma medida, se co-produzindo em conexão com ele. Forma-se toda uma cultura no sentido dessa co-produçáo que particulariza a Linha 2 e que guarda ao mesmo tempo alguns aspectos em comum com o que se passa em todo o sistema.

$$
\begin{aligned}
& \text { - Uma é mais rápida e outra é mais lenta - afirmou um usuário sobre a Linha } 2 . \\
& \text { Uma é mais bagunçada e a outra é mais tranqüila. } \\
& \text { - Qual que é mais bagunçada? } \\
& \text { — A da Baixada. } \\
& \text { - E como assim mais bagunçada? } \\
& \text { — Mais cheia, as pessoas sentadas no chão, aquela briga pra sentar. E na Linha } 1 \text { é } \\
& \text { mais tranquilo. }
\end{aligned}
$$

As quatro falas foram recortadas de conversas com usuários respectivamente em abril de 2006, maio de 2007, março de 2009 e novembro de 2005. Os dados de campo mostram que as comparaçôes são recorrentes, sempre para desvantagem da Linha 2. Por outro lado, hoje cada vez mais a Linha 1 vai também alcançando níveis de precariedade devido a problemas operacionais. Mas outras especificidades da Linha 2 estão sendo percebidas pelos usuários e também aparecem na minha observação.

\section{Duas Linhas}

Quem viaja ou já viajou na Linha 1 e na Linha 2 e ficou atento viu que o ritmo de embarque e desembarque difere nos dois casos. Na Linha 1 há um entra-e-sai constante ao longo do percurso. Já na Linha 2 a maioria embarca em algum ponto e vai direto a regiôes do Centro e da Zona Sul servidas pela Linha 1. Os passageiros da Linha 2 muito frequentemente estáo tentando alcançar essas áreas mais urbanizadas onde trabalham. Por isso observamos que a maioria desses embarques ocorre de manhã. No pico noturno os trens das duas linhas lotam no sentido oposto, do Centro-Sul para os bairros da Zona Norte.

O perfil da demanda é, portanto, diferente nos dois casos. Na Linha 2 a demanda se concentra no pico matutino que vai das 5 às 9 horas, quando ocorrem $41,6 \%$ das entradas da linha, sendo que $70 \%$ têm como destino a Linha 1. Na Linha 1 é justamente na hora do retorno dos passageiros da Linha 2 que se verifica maior demanda - entre 16 e 20 horas, quando ocorrem 36,9\% das entradas (SOUZA, 2004, 19). Souza observa que há uma "pendularidade" das entradas nas duas linhas, porém muito mais marcante na Linha 2.

A pendularidade, que envolve um movimento mútuo das duas linhas, é bem mais característica da Linha 2, que apresenta um fluxo de demanda bem assentado nos dois picos, o da manhã no sentido Pavuna-Estácio e o da noite no sentido contrário. Na Linha 1 , como vimos, há um expressivo afluxo 
de passageiros ao longo de todo o percurso, o que faz com que a distribuição da demanda seja mais equilibrada, no sentido de mais espalhada. A Linha 1 atravessa áreas mais ricas da cidade e por isso recebe quase obrigatoriamente a demanda da outra linha, exercendo uma atração que não é recíproca.

As estaçóes da Linha 2 comportam composiçóes de 8 carros, enquanto as da Linha 1 estão preparadas para receber composiçôes de apenas 6 . As interestaçôes, ou seja, os trechos entre as estações também são diferentes em cada caso. As da Linha 2 são mais longas. As estaçôes da Linha 2 são mais afastadas umas das outras, com espaços médios de $1,447 \mathrm{~km}$, enquanto as estaçóes da Linha 1 distam em média $0,871 \mathrm{~km}$ entre si (SOUZA, 2004, 13)

$\mathrm{O}$ corpo sente essa diferença quando viajamos nas duas linhas. $\mathrm{Na}$ Linha 2 a viagem é mais longa entre as paradas. É possível perceber também a maior extensão do trecho entre Triagem e Maria da Graça. Chega-se à Estação Maracanã e em seguida a Triagem, e de Triagem a Maria da Graça pode-se levar uns 5 minutos e sente-se a velocidade baixando. Essas distâncias maiores, as estaçôes elevadas ou superficiais e até o entorno mais rural podem produzir a sensação da estrada de ferro. Há um pouco de ferrovia na Linha 2 - como, aliás, comentam alguns usuários.

De fato, por várias de suas características, a Linha 2 se aproxima um pouco do conceito de metrô regional ou trem metropolitano. A Linhal seria mais rigorosamente um metrô urbano. $\mathrm{O}$ metrô urbano, como explica Alouche (2005, 82), é "um sistema elétrico sobre trilhos que atende zonas tipicamente urbanas, com uma oferta ao longo de todo o dia". Esse entre-e-sai que ocorre na Linha 1 e a que já nos referimos é uma característica marcante do metrô urbano. A tecnologia metroviária autoriza um intervalo da ordem de 90 a 120 segundos nos períodos de pico e de 3 a 5 minutos durante os vales. Trata-se de números, ao que parece, inatingíveis em qualquer linha do sistema do metrô carioca no contexto da atual crise operacional que mencionamos mas, de toda forma, o intervalo breve e a proximidade entre as estações que caracterizam o metrô urbano são aspectos da Linha 1 . $\mathrm{Na}$ Linha 2 a sinalização não é automática e por segurança os intervalos fixados têm que ser maiores.

No metrô urbano a tendência são as estaçôes subterrâneas, mas não é incomum as superficiais ou as elevadas. Como a Linha 2 percorre a periferia, foi preferível e muito mais barato aproveitar os espaços vazios da superfície para construir as estaçóes. Isso a caracteriza novamente como uma linha de metrô que serve regióes periféricas e que no próprio projeto construtivo realiza menos o conceito de metrô.

Um metrô regional ou trem metropolitano "é um sistema elétrico sobre trilhos que atende zonas mais afastadas do cento urbano, interligando municipalidades ou bairros longinquos" (ALOUCHE, 2005, 84). A intensidade da demanda não difere nos dois casos, mas a origem e o perfil mudam. O perfil da demanda do metrô regional é do tipo da que encontramos na Linha 2: pendular, com o pico matutino no sentido bairros-centro e à tarde no sentido contrário. Um exemplo de Metrô Regional é o RER da região parisiense, assim como os metrôs de Recife, Porto Alegre e Belo Horizonte. 
O metrô regional difere por sua vez do trem regional. Este é um transporte ferroviário local, como a Supervia no Rio de Janeiro. O metrô regional ou trem metropolitano tem tecnologia de metrô e uma agilidade que o separa da ferrovia. Por outro lado, o transporte metroviário se realiza mais perfeitamente no metrô urbano com seus intervalos curtos, suas estaçóes próximas e sua distribuição equilibrada de demanda. A Linha 2 é certamente uma linha de um metrô urbano, mas é interessante observar como, por características do próprio projeto da linha, por características operacionais e até pela cultura que aí foi se formando, guarda alguns aspectos que a aproximam do trem metropolitano.

No início a Linha 2 não era uma linha de metrô em toda a sua extensão. De Maria da Graça em diante não havia estações construídas, mas apenas paradas, e se utilizavam veículos mais leves e de muito menor capacidade, espécies de bondes, constituindo o que se chamava "pré-metrô". Operou-se assim de 1983 a 1987.

Em seguida, o projeto evoluiu e as estaçôes foram sendo construídas. Hoje a Linha 2 é uma linha de metrô com estações em toda a sua extensão e o mesmo tipo de material rodante é utilizado nas duas linhas. As distinçóes que mencionamos continuam, por outro lado, definidoras do contraste com a Linha 1.

Finalmente, a Linha 2 serve regióes numa mesma municipalidade que as da Linha 1, mas elas são em alguma medida "longínquas" segundo os critérios geo-sociais vigentes na cidade. Um pouco por suas características técnicas, portanto, e mais talvez por sua inserção sócio-política no contexto urbano do Rio de Janeiro, a Linha 2 se afasta um pouco do metrô por excelência, que se realiza na Linha 1.

A Linha 2 se cruza com a Linha 1, os passageiros se misturam em alguns pontos e momentos - as duas linhas se encontram e se procuram, como deve ser num sistema metroviário. Mas a Linha 2 guarda um pouco essa situação de inacabamento. São aspectos técnicos e também sociais que criam uma alteridade interessante. No contexto de um sistema pequeno e binário, essas diferenças acabam por gerar quase uma oposição - como se pode observar em muitas afirmaçóes dos usuários. De toda forma, trata-se de um contraste que vale explorar.

\section{As estações e seu entorno}

__-Você conhece as estaçôes da linha 2? _- perguntei a uma usuária.

- Estações da linha 2? Conheço.

- Tem alguma que você ache mais bonita, outra menos bonita, tem alguma preferida?

- Não. Acho que do Estácio pra cá elas não são assim muito arrumadas, né? Pintadas, assim... Agora, do Estácio pra lá já melhora.

- Na Linha 1?

- É, lá tem ventilador, relógio. O de cá é meio assim, não tem pintura. Alguns, não são todos. 
Comentando comigo sobre a Linha 2, Cristina, usuária das duas linhas observou:

A própria estação... Não sei o quê que é, você já entra em um bafão, em um lugar mais esquisito. Deve ser básico, assim, você vê as melhores estaçöes, as mais luxuosas são na Linha 1.

O calor que na chegada às estaçôes da Linha 2 pode irromper como um "bafão" é um aspecto das regióes que ela serve ao mesmo tempo que se agrava com a acolhida das estaçóes de cimento. Não se trata apenas das características técnicas dos materiais, mas das sensaçóes e dos afetos que a estética das palaformas e dos mezaninos acaba por impor. A comparação com as estaçóes da Linha 1 que fazem tantos usuários pode ser em alguma medida confirmada pela observação. As estações da Linha 1 são subterrâneas, criando seu próprio ambiente. Todas têm um visual cuidado, pastilhas ou mármore. Por outro lado, várias estaçóes da Linha 2 têm decoração de pastilhas também, de diversas cores. Dialogam entre si, criando um estilo e mostrando que houve um projeto e um cuidado na construção. De fato, não é apenas a simplicidade — ou, em alguns casos, a precariedade constatável — das estaçóes que gera esse bafo ou o clima esquisito apontados acima por Cristina, ou a feiura de que falam tantos usuários. É o calor lá fora, é também provavelmente o fato de se ter viajado num trem precariamente climatizado ou o problema das falhas operacionais na linha - tudo isso pode causar a sensação de estranheza. E ainda pode ser que o entorno tenha igualmente um papel aí. A paisagem pobre entra com o calor para compor o cenário das estações.

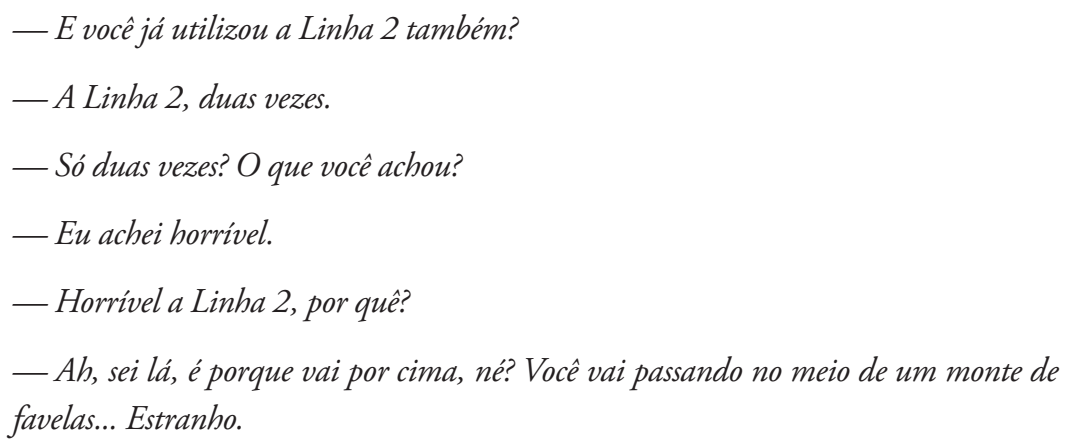

O metrô abre caminho e vai mostrando os lugares - sobretudo se as estações são superficiais ou elevadas, como na Linha 2. Eles vão emergindo e compondo a paisagem das estaçóes. Ao irromper nas estações e apresentar-e aos viajantes, o entorno da Linha 2 provoca afetos e participa da produção da sociabilidade e da comunicação no ambiente do metrô. Ele é ativo em produzir essas sensações de que falam os usuários. $\mathrm{O}$ ambiente pobre no Rio de Janeiro faz parte do metrô.

O que se vê são ruas precárias e habitações muito simples, muitas vezes inacabadas. Quem procurar vai achar outras coisas. Da Estaçáo Triagem se avistam aquelas antigas caixas d'água sobre os prédios e construçóes singulares embora muito gastas. Um usuário referiu-se ao entorno da Linha 2 como "o Rio de Janeiro genuino”. De fato, a parte urbanizada e rica da cidade é uma fatia 
mínima - e que não cessa de receber mais benefícios. Na Linha 2 é impossível ignorar a pobreza em torno - quer se ache estranho, se lamente, se pondere sobre ela ou se procure adivinhar uma força à revelia de tudo. O Rio de Janeiro se apresenta ali de forma incontornável.

Outro problema são os riscos tipicamente urbanos que rondam a linha. $\mathrm{O}$ entorno não parece ser hospitaleiro para os moradores daquelas regióes que chegam de metrô de volta do trabalho ou outros que por ali transitem. São assaltos, assassinatos, tiroteios e balas perdidas. Tanto os usuários quanto os agentes e ainda as notícias de jornais confirmam que se trata de regiôes onde muitas coisas desse tipo acontecem. Mesmo a estação Maracanã, próxima do Centro, é conhecida como tendo um entorno que seria melhor não frequentar à noite. Eu mesma já constatei isto em algumas ocasióes em que fui à UERJ de metrô. A Universidade Estadual do Rio de Janeiro fica ao lado de uma das rampas de saída da estação.

- É raro de eu pegar para o retorno å noite porque é perigosa a minha estação. A estação Maracanã é muito perigosa no acesso — comentou uma usuária.

— Ai você não vai de metrô? — perguntei.

- Eu volto de ônibus.

Comentando sobre as estaçôes mais perigosas, um usuário que costuma utilizar sobretudo a Linha 2 observou:

- Aqui da Pavuna tem essa Rubens Paiva, tem Tomás Coelho. Ali aquele pedaço, Inhaúma.

- Mas por que que é perigoso?

- Aqui em Fazenda Botafogo eu já soube de vários assaltos.

Alguns separam a estação do entorno. A presença dos agentes é um fator de tranquilidade, assim como a das câmeras.

- Porque esses guardas municipais... — disse uma usuária. Eu me sinto mais segura em metrô do que em ônibus.

- Por que?

- Até pelas câmeras, um Big Brother Metrô ajuda muito, eu me sinto mais segura.

- Tem alguma estação que você acha mais perigosa?

- Sinceramente, quem for ouvir essa gravação pode até estranhar, mas eu tenho fé no Deus que eu sigo e eu náo posso dizer pra você que eu tenho medo, porque ele toma conta de mim.

Muito comum é roubo de celular na rampa de acesso a Pavuna. Foi Ana Maria, que mora na Pavuna, que me contou esse fato e disse que ela foi roubada na rampa, embora o ladrão tenha desistido porque o celular dela é muito simples.

São diferentes as maneiras de se conviver com o problema. A experiência de um entorno ativo, contudo, faz parte da Linha 2. Essa atividade pode, 
de forma extrema, ser a intrusão de um tiro na plataforma ou de assalto nas imediaçôes da estação. Pode ser também um cenário que se impóe e se conjuga com as pastilhas coloridas, o cimento armado, as câmeras de vigilância e tudo o mais que constitui o ambiente do metrô.

\section{Percurso acidentado}

Os usuários da Linha 2 também estão sempre relatando problemas operacionais, como parada de trens nas interestações, escadas rolantes que não funcionam e, sobretudo, ar condicionado quebrado ou insuficiente. Desde o acesso à estação até a viagem no trem, há acidentes. Hoje enfrentam-se esses problema também na Linha 1, embora, ao que parece, em menor grau. Há pouco tempo, viajando na Linha 1 na direção Saens Peña, o trem em que estava parou três vezes. Nestes dias de fevereiro de 2010, em que chegamos a 50 graus, embarquei num vagáo sem ar condiconado. As pessoas se abanavam sem parar.

Nílton, em conversa na Linha 2, comentou:

- Eu noto que às vezes na Linha 2, que é da Baixada, às vezes, vira e mexe o ar condicionado tá com problema nos vagóes. Ou não funciona ou tá fraquinho. A Linha 1 , precisa ver como é que tá, ali gela pra caramba. Como hoje, hoje tá bom, né? Eu não sei se é porque o verão é muita vazão.

Em conversa numa composição da Linha 2, Rafael comentou:

- Eu nunca vi uma escada rolante lá embaixo parada, tá sempre funcionando. Aqui pra cima você, dificilmente você encontra escada rolante funcionando, somente lá no ponto final de Pavuna.

Um problema que acrescenta muito ao aspecto do acidente é o da superlotação. Já no início da pesquisa alguns usuários diziam que na Linha 2 os trens vinham cheios a qualquer hora do dia. Nos horários de pico, contudo, a situação pode atingir níveis insuportáveis de desconforto. Esse processo, que é antigo na Linha 2, já é constatável na Linha 1. Mas compreende-se como numa linha em que a demanda tem pontos mais definidos de concentração de demanda tudo possa ficar pior. Há também as limitaçóes de sinalização que impedem que os trens sejam injetados na linha com maior frequência, diminuindo o intervalo.

- Agora, o unico problema da linha 2 mesmo - afirmou Débora em entrevista na Linha 1 em abril de 2006 - é a superlotação, qualquer horário, qualquer horário, impressionante, qualquer horário.

Até hoje e cada vez mais o problema da superlotação só faz se agravar. Dois anos depois, em conversa na plataforma de Coelho Neto, comentou uma usuária:

- Várias vezes peguei o metrô lotado. Até uma vez fui fazer um trabalho na UERJ, aconteceu do metrô parar em Irajá e em vez deles mandarem um outro metrô vazio sabendo que eram sete horas da manhã, horário do tumulto, não, o próximo veio lotado. O pessoal teve que entrar e eu quase quebrei meu braço por causa dessa confusão. 
A observação-participação na estação de transferência e em outras estaçôes da Linha 2 não tem feito senão confirmar as afirmaçôes dos usuários sobre a superlotação e sobre os empurróes. $\mathrm{O}$ estilo do empurra-empurra caracteriza as viagens na Linha 2, como todos são unânimes em afirmar. Acompanha bem a situação de saturação em que a linha se encontra há muito tempo, mas não se explica totalmente por aí. Empurrar é uma escolha que se faz e acaba constituindo mesmo um estilo de viajar.

\section{Pessoas, atitudes e encontros}

Ainda como mais uma faceta do contraste entre as duas linhas, há a questão dos passageiros que cada uma traz. Muitos falam que as pessoas que frequentam as duas linhas são diferentes. Em geral são os usuários que não moram na Zona Norte que observam que há um jeito ou uma estética diferente do usuário da Linha 2, mas nem sempre. Inclusive, o pessoal da Zona Norte também comenta sobre diferenças entre atitudes das pessoas que provêm de cada linha. Por exemplo, empurrar o outro parece ser uma atitude que ocorre caracteristicamente na Linha 2, conforme reconhecido por todos, inlcusive os da Zona Norte. Há também comentários sobre outras atitutes, como jogar lixo no chão, que ocorreria mais na Linha 2. Mas nem todos os contrastes pesam contra o pessoal da Linha 2.

$$
\begin{aligned}
& \text { - O senhor acha que no metrô é diferente, mais limpo em geral? - perguntei a um } \\
& \text { usuário. } \\
& \text { - Eu acho. } \\
& \text { - Por que será? } \\
& \text { - Eu nấo sei, porque ficam constrangidos. Deve ser isso. Mas já na Linha 2, eu já } \\
& \text { observei, lá, devido infelizmente ao nivvel ser um pouco mais baixo do que o nivel que } \\
& \text { usa a Linha 1, a coisa já fica com mais liberdade. É isso aí. }
\end{aligned}
$$

Cristina, que mora na Zona Sul e utiliza com frequência a Linha 2 para ir ao trabalho, observou numa conversa sobre assentos preferenciais:

- Na linha 2 é selva, é selva, ninguém levanta não. Aqui (Linha 1) eu ainda vejo o pessoal levantar pra... Na linha 2 não tem diferença não. As pessoas estão cansadas, sentam no chão, no banco de idoso.

A Linha 2 pode lembrar um pouco o trem suburbano do Rio de Janerio. Já por algumas características técnicas evoca o trem, como vimos. Alguns usuários apontam isso. Um deles disse que se sentia "num trem melhorado". Não é só, contudo, a questão da técnica que constrói essa proximidade. É um conjunto de atitudes, um tipo de subjetividade que parece se produzir nas viagens que singulariza a Linha 2, embora não separe totalmente o estilo que se desenvolve ali daquele que parece predominar no metrô em geral desde os seu inícios. $\mathrm{O}$ metrô costuma ser limpo e ordeiro, aliás em contraste com todos os outros lugares da cidade, e não só o trem ou o ônibus. A Linha 2 também. Os passageiros da Linha 2 não agem em franca oposição aos da Linha 1, a oposição não é clara ou sem nuances. Por outro lado, na Linha 2 esse clima ordeiro pode não 
se realizar perfeitamente. Minha experiência na pesquisa e mesmo antes, como usuária, mostra com clareza, por exemplo, que existe o empurra-empurra na Linha 2 evocado pelos usuários.

Alguns usuários falam também do aspecto das pessoas na Linha 2, sua maneira de vestir: shorts, roupa mais simples. Ora, esse visual do pessoal da Linha 2 é certamente encontrável nas viagens da Linha 1. Parece-me que o que se passa é que na Linha 1 existe uma variedade maior de estilos, tanto na aparência quanto na atitude. Devido ao perfil mais fragmentado da demanda, a Linha 1 recebe gente em diversos pontos do trajeto e as libera constantemente, renovando a população de viajantes nesse entra-e-sai. Também nesse aspecto, a Linha 1 é uma linha mais típica de metrô. Por sua composição mais heterogênea, ela se apresenta como mais fortemente urbana porque mais misturada, mais diversa.

Se os passageiros da Linha 1 afluíssem por sua vez com mais frequência à Linha 2, teríamos uma mistura maior ali também. Um usuário comentou que o pessoal da Linha 1 é mais "selecionado". Entendo que se costuma empregar e se empregou aqui esse termo num sentido positivo, indicando que as pessoas são de melhor nível ou mais educadas, como muitos observaram sobre os passageiros da Linha 1 . Mas, de fato, há menor seleção na Linha 1 , e mais mistura.

Assim, a sociabilidade que se desenvolve na Linha 2 tem aspectos que diferem em algum grau daquela que encontramos no metrô até agora, embora se tempere e se contagie também com ela. Poderíamos dizer que na Linha 2 há mais reconhecimento. Claro que as descontinuidades estão ativas ali também, já que as portas dos vagóes trazem sempre o inesperado. Trata-se de um aspecto importante do transporte coletivo: levar para longe e distribuir os passageiros, produzindo um meio diverso no veículo que os conduz (CAIAFA, 2002). Vemos ao mesmo tempo que há doses de variedade em cada caso da experiência de viajar em coletivo e maneiras diferentes de realizar essa experiência.

José Luiz Braga (1994), tratando da comunicação face a face, mostra como o que ele chama "dispositivos conversacionais" envolvem os papéis que os participantes vão assumindo nas conversas. Ele distingue o "papel representado" do "papel desempenhado". O primeiro é aquele que o participante traz de situaçóes anteriores, enquanto o papel desempenhado se desenrola no contexto das conversaçóes. Ele assinala que ocorrem interferências mútuas entre esses dois papéis. $\mathrm{Na}$ situação em que conversamos com estranhos, característica da comunicação no transporte coletivo, a definição e a eleição de papéis tendem a ser mais complexas (CAIAFA, 2007). As descontinuidades que se estabelecem nos meios diversos dos encontros urbanos podem não exibir uma inserção claramente legível. Livramo-nos em algum grau de nossa identidade quando estamos entre estranhos, embora certas marcas possam permanecer legíveis.

Os passageiros da Linha 2 são mais selecionados do ponto de vista da variedade urbana. Como as regióes que a linha serve não são atrativas para chamar visitantes e misturar mais os passageiros, algumas continuidades se 
estabelecem na composição da população dos vagóes. Os veículos que vão ter às periferias numa cidade em geral podem se caracterizar por essa seleçáo daí também a lembrança do trem que pode ocorrer a passageiros na Linha 2.

Poderíamos dizer, apoiando-nos no texto de Braga, que nos processos comunicativos que têm lugar na Linha 2, há chances de que o papel representado tenha um lugar particularmente expressivo. Os passageiros podem ser mais facilmente identificados por sua inserção, a sociabilidade que se desenvolve se baseia mais no reconhecimento.

Em outro trabalho (CAIAFA, 2006) mostrei como as conversaçóes no metrô envolvem uma polidez. São desconhecidos num ambiente sóbrio que conversam, se calam e se observam. Ora, na Linha 2 já experimentei muitas vezes os aspectos amenos dessas conversaçóes breves e polidas. Ali também se passa assim, não há dúvida. Já experimentei os empurrôes e também as incertezas que o entorno perigoso impóe. De fato, a sociabilidade e a comunicação na Linha 2 envolvem toda essa complexidade.

- Eu acho que aqui pra cima as pessoas são mais sociáveis — observou um usuário em conversa na Linha 2. Lá pra baixo as pessoas são mais secas. Não sei se é a preocupação de chegar na hora, as pessoas não conversam. Chegam às vezes até a ser mal educadas, porque pisam no seu pé, esbarram em você e nem pedem desculpa. Acho incrivel... amassa o seu calo na maior cara-de-pau, caramba...vai com uma estupidez.

- Então você acha que se conversa mais na 2 que na 1? - perguntei a Narciso.

- Eu acho que sim. O pessoal da Linha 2 conversa mais.

- Por que será?

- É porque, não sei, são mais pobres e se unem melhor. Acho que se unem melhor. Eu não sei, eu tenho visto, na Linha 2 dificilmente você vem e não vê uma pessoa conversando. Conversa um assunto, conversa outro. Tem pessoas que encostam perto da gente também, parece que nem conhece, é sisudo, não fala nada. Eu também, se eu puxar um assunto e a pessoa não aceitar, eu também esqueço.

\section{Construção de um estilo}

Há um clima que se instaura na Linha 2 e que, seguindo as afirmaçóes dos usuários e a observação direta, envolve diversos componentes: a acolhida das estaçôes (elevadas ou superficiais e por vezes predominando o cimento), o calor característico da região servida pela linha, as falhas operacionais (sobretudo o ar-condiconado defeituoso ou desligado), a superlotação, a atitude das pessoas (os empurróes, mas também uma maior proximidade entre elas, além da maior presença de lixo) e o entorno pobre e por vezes perigoso.

É possível compreender o contraste entre as linhas como resultado de um favorecimento concedido a regióes mais urbanizadas da cidade. Sem dúvida, esse processo está presente na produção dessa segunda linha do sistema. Não se trata só, contudo, do projeto construtivo. A produçáo da Linha 2 como segunda linha diz respeito a circuntâncias anteriores ao metrô e que vêm elegendo as 
regiôes litorâneas, umas mais que as outras, como regióes privilegiadas. Essas áreas urbanizadas não cessam de receber mais e mais novos benefícios da urbanização. Observando os contrastes apontados pelos usuários, vemos que a Linha 2 resultou mesmo mais precária, seguindo essa partilha desigual que predomina na cidade. Por outro lado, vimos que a Linha 2 não foi planejada inicialmente como linha de metrô urbano pesado, o que justificaria sua inferioridade operacional, por exemplo. Não se explica, contudo, por que ela foi mantida — até hoje, não se adicionou a sinalização automática. Adivinha-se que talvez imperativos financeiros tenham tido um papel nesse caso, mas a questão permanece. Seria preciso considerar também que, como vimos, é possível descobrir todo um cuidado na elaboração de uma estética na construção das estaçôes da Linha 2 - as pastilhas, os jogos de cores - mesmo que com resultados mais modestos.

No mesmo golpe, a Linha 2 não é feita apenas desses determinantes, ela também se produz com a própria frequentação dos usuários, com as atitudes das pessoas que vão compondo a paisagem física e social daquele lugar do sistema metroviário. Um ambiente não se oferece pronto para ser habitado por um sujeito, as vai se produzindo com ele. $\mathrm{Na}$ outra direção, os lugares são também fatores ativos de produção de subjetividade. Nós nos tornamos em parte o que o ambiente nos sugere e este se constrói com as nossas atitudes quando o frequentamos. Varela (1995) escreve que há uma co-implicação entre o meio e o sujeito.

$\mathrm{Na}$ Linha 2 as atitudes das pessoas vão construindo igualmente o lugar. Assim, o empurra-empurra, o problema do lixo (que como usuária eu mesma constatei, embora não ache que seja tão expressivo), a coisa "selvagem" contribuem para o clima geral na linha. É um processo complexo e vê-se como essas atitudes também se explicam em parte pelo fato de que essas regióes sempre foram preteridas e mesmo de que a Linha 2 em alguma medida também é.

Os bairros servidos pela Linha 2 não conseguiram atrair visitantes. Ali o metrô não levou gente que vem de longe, ao menos não expressivamente. $\mathrm{O}$ desenvolvimento desigual que caracteriza desde o início o processo de urbanização no Rio de Janeiro está na origem desse tipo de seleçáo que acaba ocorrendo nas viagens e de certa forma neutraliza as forças diferenciadoras da cidade e do transporte coletivo. Por outro lado, apesar dos percalços das viagens na Linha 2, os usuários constantemente reconhecem a importância de poder contar com o metrô. As outras opçóes são os trens e os ônibus, cada vez mais precários e expostos a todo tipo de violência. Por enquanto, o metrô ainda é visto como mais vantajoso que esses outros meios. Além disso, há a aventura da própria viagem, que também tem seu peso para quem sabe fruir da convivência num veículo coletivo. ${ }^{4}$

A abertura da Linha 2 - mesmo com características de segunda linha — tem alguma incidência sobre os trajetos na cidade e em algum grau força uma partilha. É fato que historicamente a cidade se desenvolveu produzindo desigualdade e o metrô não pode ir mais fundo para compor novas paisagens nas regióes que ele afeta. Mistura, contudo, em algum grau os passageiros, 
mesmo que não completamente, e os leva para onde talvez poderão desafiar uma ordem injusta e há tempo estabelecida. Quanto mais as interferências puderem ser recíprocas - e a mistura dos passageiros se faça com ressonâncias nos dois ou mais lados - mais o metrô cumprirá sua função urbanizadora, diferenciadora. O metrô se realiza muito nas transferências entre as linhas, suas correspondências, mesmo que haja duas linhas apenas.

\section{Notas}

${ }^{1}$ Este trabalho se insere no âmbito da pesquisa sobre processos comunicativos no metrô do Rio de Janeiro que realizo com o apoio do CNPq. Uma primeira versão foi apresentada no XIX Encontro da Compós, na PUC-Rio, cidade do Rio de Janeiro, em junho de 2010.

${ }^{2} \mathrm{O}$ metrô do Rio de Janeiro foi concedido à iniciativa privada em 1998 e desde então a concessionária Metrô Rio realiza a operação do sistema. Em 2008 o contrato de concessão foi renovado por mais 20 anos.

3 As estações da Linha 2 são: Pavuna, Engenheiro Rubens Paiva, Acari/Fazenda Botafogo, Coelho Neto, Colégio, Irajá, Vicente de Carvalho, Thomaz Coelho, Engenho da Rainha, Inhaúma, Del Castilho, Maria da Graça, Triagem, Marcanã e São Cristóvão. As 19 estaçóes da da Linha 1 são: Saens Peña, São Francisco Xavier, Afonso Pena, Estácio/RioCidadeNova, Praça Onze, Central, Presidente Vargas, Uruguaiana, Carioca, Cinelândia, Glória, Catete, Largo do Machado, Flamengo, Botafogo, Cardeal Arcoverde, Siqueira Campos, Cantagalo e General Osório.

${ }^{4}$ Explorei este poto em "Solidão Povoada". 


\section{Referências Bibliográficas}

ALOUCHE, Peter Ludwig. Desenvolvimento tecnológico em sistemas metroferroviários. Transporte metroferroviário no Brasil: situação e perspectivas. São Paulo: ANTP/BNDES, Série Cadernos Técnicos, vol 2, 78-114, julho 2005.

BRAGA, José Luiz. Sobre a conversação. In: FAUSTO NETO, Antonio; BRAGA, José Luiz; PORTO, Sérgio Dayrell (Orgs.). Brasil: comunicação, cultura e política. Rio de Janeiro: Diadorim, 1994.

CAIAFA, Janice. Jornadas Urbanas: exclusão, trabalho e subjetividade nas viagens de ônibus na cidade do Rio de Janeiro. Rio de Janeiro: Editora FGV, 2002.

CAIAFA, Janice. Solidão povoada: viagens silenciosas no metrô do Rio de Janeiro. Contemporanea/Revista de Comunicação e Cultura, vol. 4, n. 2, 45-64, dezembro 2006

CAIAFA, Janice. Aventura das cidades: ensaios e etnografias. Rio de Janeiro: Editora FGV, 2007.

CAIAFA, Janice. Tecnologia e sociabilidade no metrô. Revista da Associação Nacional de Programas de Pós-Graduação em Comunicação/Ecompós. Brasília, v. 11, n. 1, 1-15, janeiro-abril 2008.

SOUZA, Alessandro de Santana Moreira de. Deslocamento em contrafluxo e dificuldade de embarque na avaliação de desempenho em transporte público: o caso da Linha 2 do metrô do Rio de Janeiro. Dissertação de Mestrado. Rio de Janeiro, COPPE/UFRJ, 2004.

VARELA, Francisco. Sobre a competência ética. Lisboa: Ediçóes 70, 1995. 